\title{
Evidence for Secondary Hyperparathyroidism in Idiopathic Hypercalciuria
}

\author{
Fredric L. Coe, Janet M. Canterbury, John J. Firpo, and Eric Reiss \\ From the Department of Medicine, Michael Reese Hospital and Medical Center \\ and the University of Chicago, Pritzker School of Medicine, \\ Chicago, Illinois 60616
}

A B S T R A C T Circulating levels of immunoreactive parathyroid hormone ( $\mathrm{PTH})$ were measured in 40 patients with idiopathic hypercalciuria (IH) before and during reversal of hypercalciuria with thiazide, and in four normal subjects before and during induction of hypercalciuria with furosemide. 26 patients with $\mathrm{IH}$ had elevated serum PTH levels. The remaining patients had normal levels. Although the correlation was not complete, high PTH levels were generally found in patients who had more severe average urinary calcium losses. When initially elevated, PTH levels fell to normal or nearly normal values during periods of thiazide administration lasting up to 22 months. When initially normal, PTH levels were not altered by thiazide. Reversal of hyperparathyroidism by thiazide could not be ascribed to the induction of hypercalcemia, since serum calcium concentration failed to rise in a majority of patients. Renal hypercalciuria produced by furosemide administration elevated serum PTH to levels equivalent to those observed in patients with IH.

The findings in this study help to distinguish between several current alternative views of $\mathrm{IH}$ and its relationship to hyperparathyroidism. Alimentary calcium hyperabsorption cannot be the major cause of $\mathrm{IH}$ with high PTH levels, because this mechanism could not elevate PTH. Idiopathic hypercalciuria cannot be a variety of primary hyperparathyroidism, as this disease is usually defined, because PTH levels are not elevated in all patients and, when high, are lowered by reversal

This work was presented in part at the Annual Meeting of the Association of American Physicians, Atlantic City, N. J., May 1971.

The present address of Dr. Canterbury and Dr. Reiss is Department of Medicine, University of Miami School of Medicine, Miami, Fla.

Received for publication 1 August 1972 and in revised form 19 September 1972. of hypercalciuria. Primary renal loss of calcium could explain the variable occurrence of reversible hyperparathyroidism in IH, since renal hypercalciuria from furosemide elevates serum PTH in normal subjects. Consequently, a reasonable working hypothesis is that $\mathrm{IH}$ is often due to a primary renal defect of calcium handling that leads, by unknown pathways, to secondary hyperparathyroidism.

\section{INTRODUCTION}

Idiopathic hypercalciuria $(\mathrm{IH})^{1}$ is a syndrome characterized by normocalcemia and hypercalciuria that is unexplained by an established cause such as sarcoidosis, renal tubular acidosis, excessive intake of vitamin $D$ or calcium, malignancy, immobilization, or rapidly progressive osteoporosis (1). Kidney stones are very common, and there is a tendency towards hypophosphatemia. The syndrome occurs in approximately $3 \%$ of normal persons and in $30-40 \%$ of patients with nephrolithiasis $(2-4)$.

The mechanism of hypercalciuria has not been established. At present, three theories deserve special consideration. (a) Gastrointestinal calcium absorption is generally elevated in $\mathrm{IH}(5,6)$, and in certain patients hyperabsorption appears to be the predominent mechanism of hypercalciuria (7). (b) Idiopathic hypercalciuria resembles primary hyperparathyroidism except that, by definition, hypercalcemia is absent. Because of this resemblance and the known variability of serum calcium levels in hyperparathyroidism, it has long been suspected that many patients who appear to have $\mathrm{IH}$ have instead a normocalcemic variety of primary hyperparathyroidism $(8,9)$. (c) Excessive renal calcium loss

\footnotetext{
${ }^{1}$ Abbreviations used in this paper: IH, idiopathic hypercalciuria; $\mathrm{PTH}$, parathyroid hormone.
} 
can occur by virtue of defective tubular calcium reabsorption in interstitial and medullary renal diseases (10). The notion that $1 \mathrm{H}$ is due to defective renal tubular calcium reabsorption has not been critically tested. In an important experiment by Finn, a kidney from a father with $\mathrm{IH}$ was transplanted to the son (11). The son did not develop hypercalciuria after transplantation, suggesting that the primary defect was extrarenal. However, this single observation does not exclude the possibility that, in many patients, hypercalciuria is of renal origin.

We have approached the problem of the pathogenesis of $\mathrm{IH}$ by studying parathyroid function using a sensitive radioimmunoassay for parathyroid hormone $(\mathrm{PTH})$ (12). If excessive gastrointestinal absorption of calcium is the primary event in $\mathrm{IH}$, serum $\mathrm{PTH}$ should be suppressed. In sarcoidosis, a hypercalciuric state generally considered to be due to alimentary hyperabsorption of calcium, serum PTH levels are low (13). If normocalcemic primary hyperparathyroidism is the basis of IH, serum PTH levels should be uniformly high and should be unaffected by reversal of the hypercalciuria. If defective tubular calcium reabsorption engenders $\mathrm{IH}$, serum $\mathrm{PTH}$ levels should be normal or high, and, when high, PTH should become normal when hypercalciuria is reversed.

In the present study we report serum PTH levels in patients with IH before and after hypercalciuria has been reversed by pharmacological means. In addition, data are presented on the response of serum PTH levels in normal subjects to the induction of hypercalciuria with furosemide, a potent diuretic agent that produces hypercalciuria principally by diminishing distal renal tubular calcium reabsorption. ${ }^{2}$

\section{METHODS}

\section{Patients}

40 patients with IH were studied. They were derived consecutively from a large population of patients with nephrolithiasis. The diagnostic criteria for IH were the following: (a) presence of unequivocal hypercalciuria, defined by greater than $300 \mathrm{mg} / 24 \mathrm{~h}$ of urinary calcium excretion in men, $250 \mathrm{mg} / 24 \mathrm{~h}$ in women, or $4 \mathrm{mg} / \mathrm{kg}$ body weight per $24 \mathrm{~h}$ in either sex, with patients ingesting a customary diet containing no more than $\frac{1}{2}$ quart of milk and no more than two ordinary servings of other dairy products per day; $(b)$ known causes of hypercalciuria such as sarcoidosis, rapidly progressive osteoporosis, excessive vitamin $\mathrm{D}$ or calcium ingestion, immobilization, hyperthyroidism, renal tubular acidosis, and malignancy could be excluded; (c) normocalcemia, defined by at least three normal serum calcium values, was present. Patients with $\mathrm{IH}$ were excluded from study if there was renal damage evidenced by diminished creatinine clearance, elevated serum creatinine, prior surgical excision of substantial amounts of

\footnotetext{
${ }^{2}$ Dirks, J. H. Personal communication.
}

renal tissue, or radiographic evidence of persistent urinary tract obstruction.

\section{Normal subjects}

Normal values were derived from normal subjects who were not under medical care and had no known illnesses. Four normal, healthy young men served as experimental subjects for the study of the effect upon serum PTH levels of hypercalciuria due to the administration of furosemide. In each case, a thorough medical history was obtained and a physical examination was performed by one of us.

\section{Experimental design}

Studies of $I H$. All patients were studied as outpatients. Initial evaluation of each patient was based upon four $24 \mathrm{~h}$ urine collections and four corresponding blood samples. Serum calcium, phosphorus, and creatinine levels and $24 \mathrm{~h}$ creatinine clearance were measured three times. Urinary calcium excretion was measured twice. Serum PTH was measured once. After this initial evaluation, patients were treated with trichlormethiazide (naqua), $2 \mathrm{mg}$ orally, given twice daily. Subsequent measurements of urine calcium excretion, serum calcium, PTH, phosphorus and creatinine, and $24 \mathrm{~h}$ creatinine clearance were made at 3 or 4 month intervals.

Furosemide-induced hypercalciuria. $24 \mathrm{~h}$ urine calcium excretion, serum calcium, PTH, creatinine, and phosphorus levels, and $24 \mathrm{~h}$ creatinine clearance were measured on 3 consecutive days. Each subject then received furosemide, $40 \mathrm{mg}$ orally, given twice daily, and supplemental sodium chloride, $50 \mathrm{mEq}$ orally, given three times daily, for 9 consecutive days. All measurements were then repeated during the 7 th, 8 th, and 9 th days of treatment.

\section{Techniques of sample collection}

Urines for calcium were collected in polypropyline bottles containing $10 \mathrm{ml}$ of concentrated hydrochloric acid. Subjects were instructed in appropriate techniques of urine collection. Actual times of initiation and completion of each sample were recorded by the patient. All values were then computed to $24 \mathrm{~h}$. Blood samples were drawn between $7: 30$ and 9:30 a.m. at the conclusion of each urine collection, while patients were in the postabsorptive state. A tourniquet for blood drawing was left in place no longer than $30 \mathrm{~s}$; blood samples were not drawn until $2 \mathrm{~min}$ after release of the tourniquet. Blood and urine samples for calcium were diluted within $30 \mathrm{~min}$ of collection using automatic diluters in which samples contact parts made only of Tygon (Hobbs Corp., Miami, Fla.).

\section{Laboratory methods}

Calcium concentration was determined in serum and urine using atomic absorption spectrophotometry. All dilutions were made in a lithium-strontium diluent. Samples were each diluted three times, and each dilution was analyzed separately. If the three dilutions did not agree within 0.1 $\mathrm{mg} / 100 \mathrm{ml}$, continued dilutions were made until three consecutive dilutions agreed within this limit. Ionized calcium concentration was measured using a flow-through liquid membrane electrode (Orion, series 98; Orion Research, Inc., Cambridge, Mass.). Circulating immunoreactive PTH was measured by a radioimmunoassay described in detail elsewhere (12). Serum PTH levels in this assay are in units of microliter-equivalents per milliliter of a standard, refer- 
ence, hyperparathyroid serum. Normal range is 10-60. Phosphorus and creatinine concentration of blood and urine were determined by Autoanalyzer (Technicon Co., Inc., Tarrytown, N. Y.) methodology.

\section{RESULTS}

Studies of idiopathic hypercalciuria. In 26 of the 40 patients, urinary calcium excretion was elevated either in absolute amount or per kilogram body weight on both occasions that $24 \mathrm{~h}$ urine calcium excretion was measured (persistent hypercalciuria) (Fig. 1). In the remaining 14 patients, hypercalciuria was present on one occasion but absent on the other (intermittent hypercalciuria) (Fig. 2). Serum PTH values are shown for each patient along with an identifying patient number, drawn from the general stone program, and used later in this report for identifying patients during the course of treatment.

Serum PTH was higher among persistent than among intermittent hypercalciuric patients (Fig. 3). Mean serum PTH was significantly higher in the persistent group $(P<0.01)$, and virtually all values above 100 occurred in patients with persistent hypercalciuria.

Mean values of serum calcium, phosphorus, and creatinine, and $24 \mathrm{~h}$ creatinine clearance are shown in Table I. Although all patients were normocalcemic, serum calcium levels were significantly higher in patients with high PTH than in patients with low PTH or in normal subjects. Significant hypophosphatemia was present to an equal extent in patients with high and normal PTH levels. Serum creatinine and 24-h creatinine clearances were normal in both types of patients with IH.

12 patients with initially high PTH levels were observed during treatment with trichlormethiazide (Fig. 4). Urinary calcium excretion decreased to normal in every case, generally within 3 months. Serum calcium levels increased above control values during treatment in three patients; calcium concentration fell in two patients. One of the patients in whom calcium levels rose, no. 37, had a peculiar combination of hypocalcemia, hypercalciuria, and extremely high serum PTH

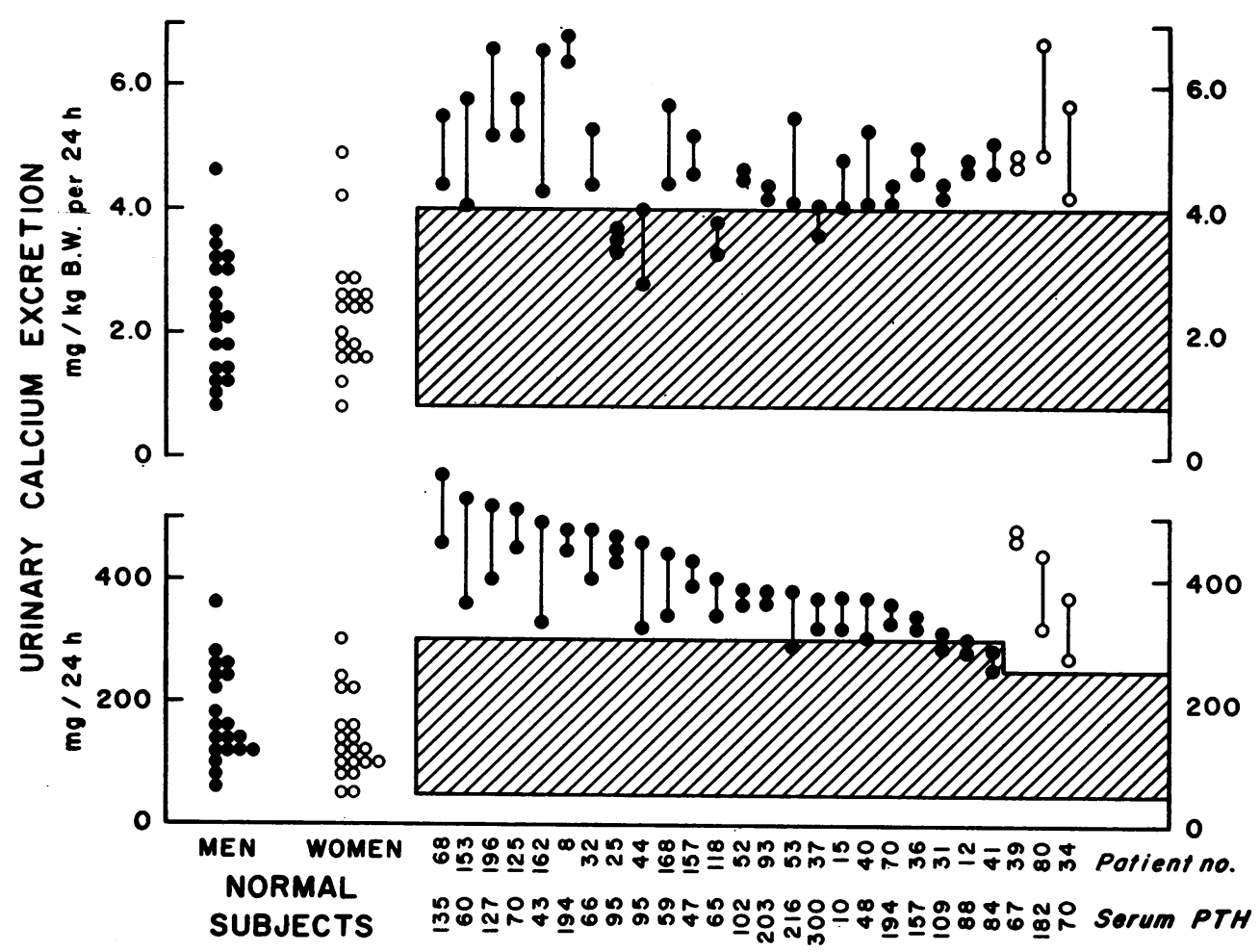

FIgURe 1 Urinary calcium excretion and serum PTH levels in patients with persistent hypercalciuria. Urinary calcium excretion of each patient exceeded the range of normal for our own control subjects as well as the usual upper limits of normal: $300 \mathrm{mg} / 24 \mathrm{~h}$ (men, closed circles), $250 \mathrm{mg} / 24 \mathrm{~h}$ (women, open circles), or $4 \mathrm{mg} / \mathrm{kg}$ body weight (B. W.), either sex. Three normal subjects were hypercalciuric. Each patient was hypercalciuric on all occasions that urine calcium excretion was measured. Serum PTH levels are shown for each patient along with an identifying patient number used in Figs. 4 and 5. 


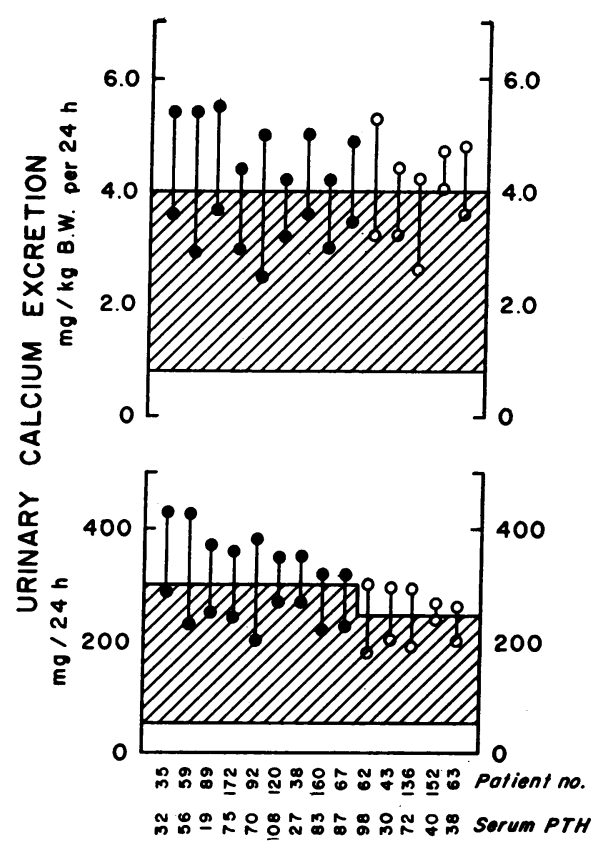

FIGURE 2 Urinary calcium excretion and serum PTH levels in patients with intermittent hypercalciuria. Symbols as in Fig. 1. Each patient had one elevated and one normal value for urinary calcium excretion. B. W., body weight.

levels. This patient will be reported in detail elsewhere. With one exception, serum PTH level became normal or nearly normal during treatment. The single exception is the unusual patient, no. 37; his serum $\mathrm{PTH}$ fell only slightly during 22 months of treatment.

Since trichlormethiazide could reduce serum $\mathrm{PTH}$ either by a nonspecific pharmacological action or by reversal of hypercalciuria, we studied the effect of the drug on serum PTH in seven patients with hypercalciuria and normal serum PTH levels (Fig. 5). Reversal of

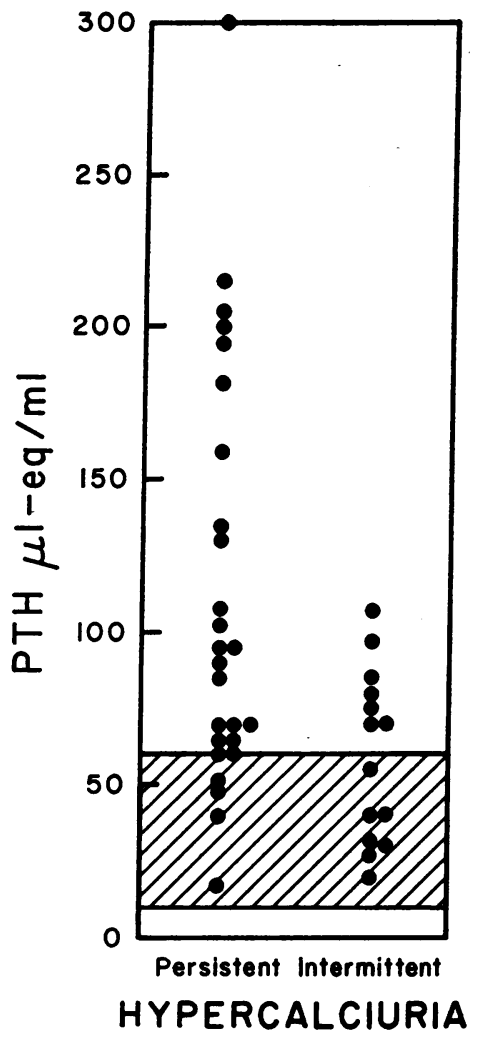

FIGURE 3 Comparison of serum PTH levels in patients with persistent and intermittent hypercalciuria. Each point represents one PTH measurement in a single patient. $\mathrm{Pa}$ tients with persistent hypercalciuria had higher average PTH levels than those with intermittent hypercalciuria $(111 \pm 13.4$ (SE), persistent ; $59.6 \pm 7.7$ (SE), intermittent hypercalciuria ; $t=3.32, P<0.01$ ).

hypercalciuria occurred in all but one of these subjects. Serum PTH levels remained constant. Serum calcium concentration rose slightly in four of the seven patients.

TABLE I

Serum Calcium, Phosphorus, and Creatinine, and Creatinine Clearance in Patients with Normal and Elevated PTH Levels

\begin{tabular}{|c|c|c|c|c|}
\hline \multirow[b]{2}{*}{ Subjects } & \multicolumn{3}{|c|}{ Serum* } & \multirow{2}{*}{$\begin{array}{l}\text { Creatinine } \\
\text { clearance* }\end{array}$} \\
\hline & Calcium & Phosphorus & Creatinine & \\
\hline & $\mathrm{mg} / 100 \mathrm{ml}$ & $m g / 100 \mathrm{ml}$ & $\mathrm{mg} / 100 \mathrm{ml}$ & liters $/ 24 h$ \\
\hline Normal subjects & $9.42 \pm 0.03$ & $3.84 \pm 0.06$ & $0.96 \pm 0.02(95)$ & $210 \pm 8$ \\
\hline Low PTH patients & $9.41 \pm 0.03$ & $3.34 \ddagger \pm 0.08$ & $0.97 \pm 0.02$ & $195 \pm 7 \quad(48)$ \\
\hline High PTH patients & $9.56 \S \pm 0.03$ & $3.26 \| \pm 0.07$ & $0.95 \pm 0.01(72)$ & $204 \pm 5 \quad(72)$ \\
\hline
\end{tabular}

Number of measurements shown in parentheses.

$*$ Mean $\pm 1 \mathrm{SE}$

$\ddagger$ Below normal; $t=4.68, P<0.01$.

$\S$ Exceeds low PTH and normal subjects; $t=3.09, P<0.01$.

$\|$ Below normal; $t=6.19, P<0.01$. 
If hyperparathyroidism in IH is secondary, it should be due to hyperplasia rather than adenoma, and should, therefore, be suppressed by calcium infusion (14). Four subjects with IH and elevated PTH levels received intravenous calcium at a rate of $4 \mathrm{mg} / \mathrm{kg}$ per $\mathrm{h}$ (Table II). All four patients were studied 10 days after temporary interruption of thiazide treatment. Serum PTH levels fell in each case. One of the patients, no. 37 , is

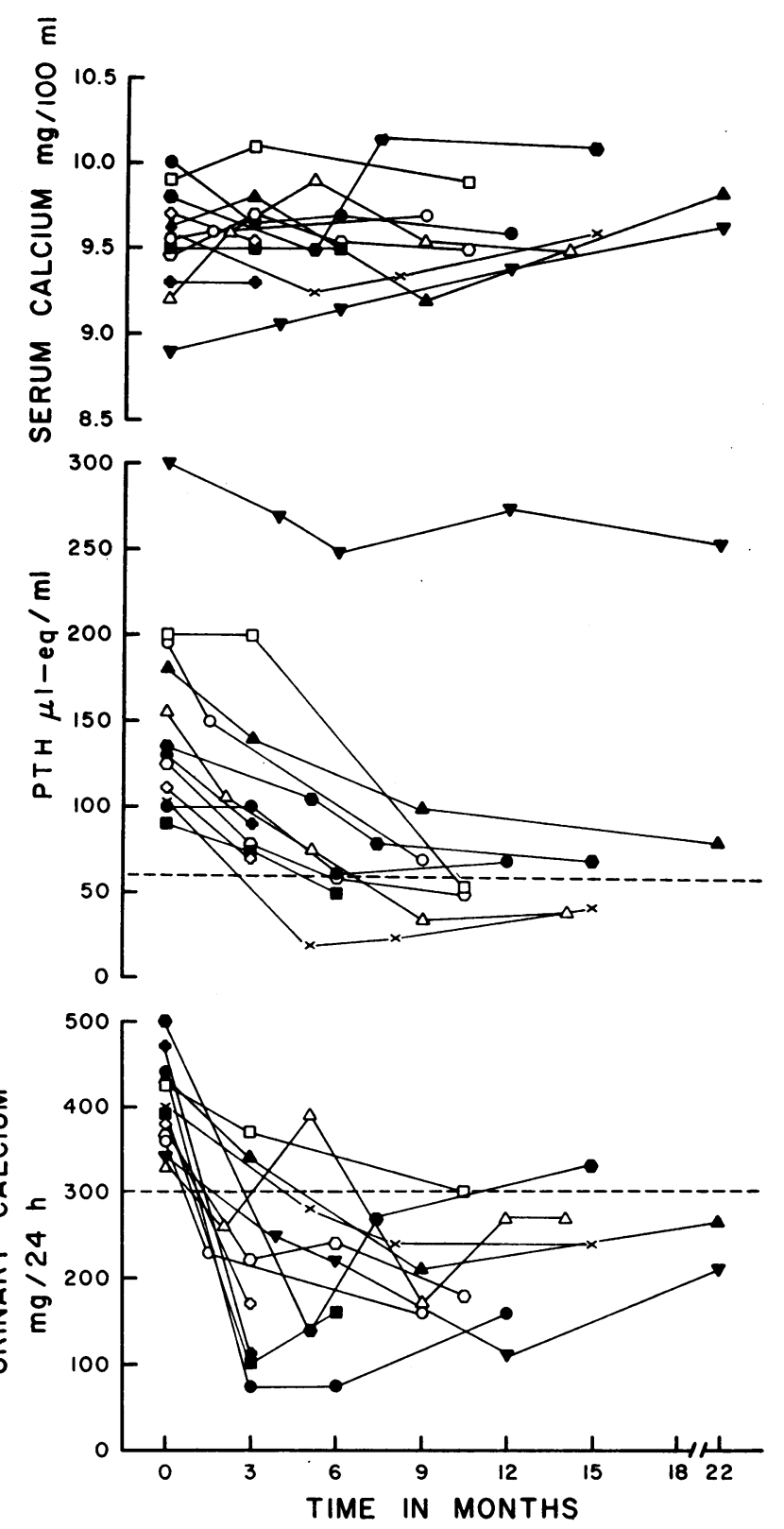

FIGURE 4 Effects of thiazide upon urinary calcium excretion, serum PTH, and serum calcium concentration in patients with IH and elevated PTH. Symbols denote individual patients (see below). Urinary calcium excretion fell in each patient, generally attaining normal values. Serum PTH levels attained normal or near normal values in all but one case. The single exception (no. 37) has a peculiar syndrome of slight hypocalcemia, hypercalciuria, and extremely elevated PTH levels. Patient identification: $\nabla=37, \square=93, \bigcirc=70, \Delta=80$, $\triangle=36, \quad \times=44, \quad=25, \square=172$, closed hexagon $=68$, open hexagon $=52$, open cross $=31$, closed cross $=196$. 

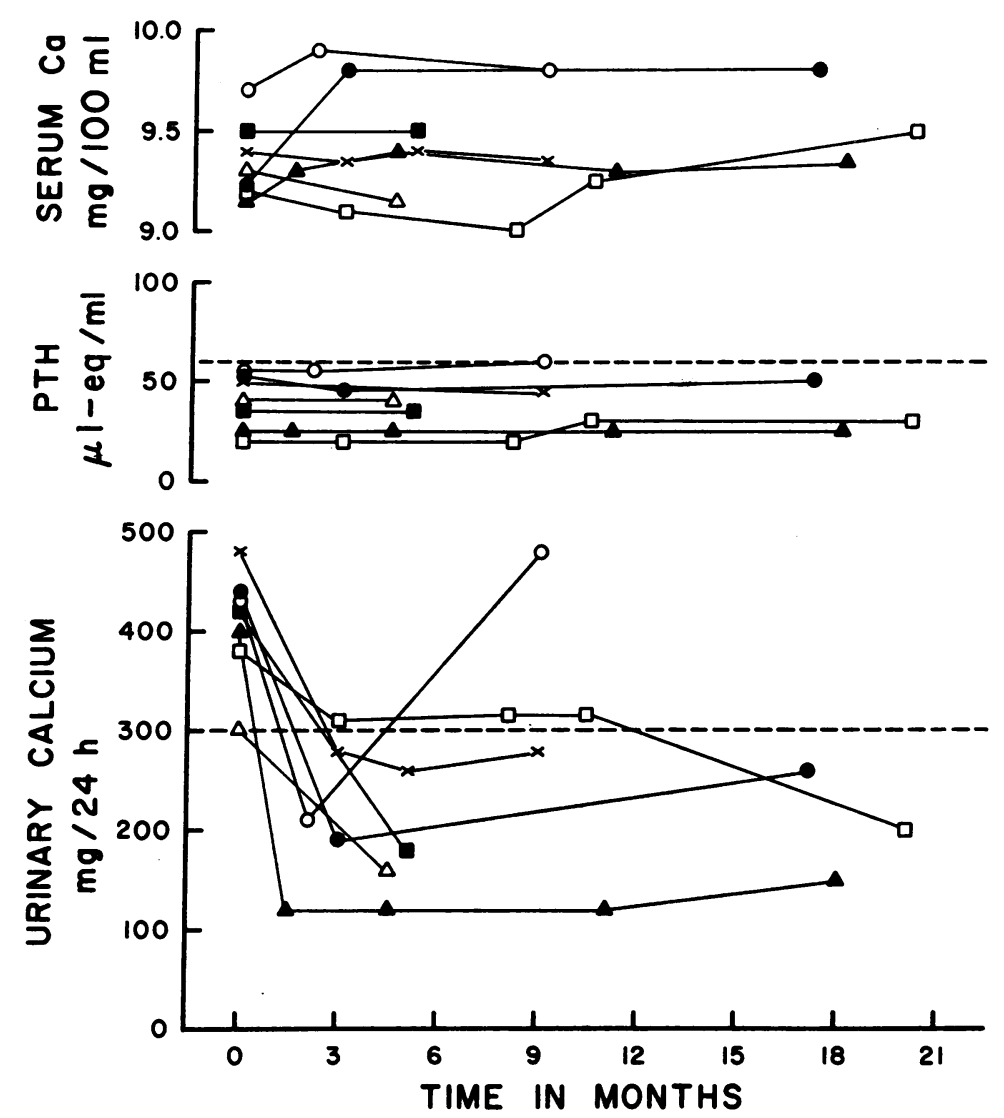

FIGURE 5 Effects of thiazide upon urinary calcium excretion, serum $\mathrm{PTH}$, and serum calcium concentration in patients with IH and normal PTH. Symbols refer to patient numbers (see below). Urinary calcium excretion fell in six of the seven patients. Serum PTH levels were unaltered. Symbols : $O=168, \square=35, x=157, \Delta=152, \quad \bullet=59, \square=89, \Delta=38$.

of particular interest, since PTH levels did not fall during sustained thiazide treatment.

Furosemide-induced hypercalciuria. Urinary calcium excretion increased in all four normal subjects given furosemide (Fig. 6). Serum PTH rose in every subject, generally attaining levels comparable to those observed in patients with persistent IH. Total and ionized serum calcium remained constant. Serum phosphorus and $24 \mathrm{~h}$ creatinine clearance (not shown) also remained constant during furosemide administration.

\section{DISCUSSION}

Occurrence of hyperparathyroidism in $I H$. The interpretation of these data depends on the validity of the $\mathrm{PTH}$ assay. PTH is secreted into the circulation as the native 84 amino acid peptide (15). Metabolism of the hormone generates one or more immunoreactive peptide fragments $(15,16)$. Antisera to PTH contain antibodies that possess varying affinities for the intact hormone and its fragments. Since antisera vary widely in their specificity for hormone and fragment recognition, divergent results reported from various laboratories are not unexpected (17). A recent preliminary report has suggested that the majority of immunoreactive $\mathrm{PTH}$ in the peripheral circulation is biologically inert, but the biologic activity of $\mathrm{PTH}$ fragments requires further study (18).

The assay used in this study is characterized by excellent discrimination between normal and abnormal sera and by high sensitivity of $\mathrm{PTH}$ responses to physiologic stimuli $(12,19)$. A critical evaluation of the usefulness and limitations of this assay has been presented elsewhere (14). Approximately $20 \%$ of immunoreactive circulating $\mathrm{PTH}$ is the complete $\mathrm{PTH}$ molecule; the remainder represents fragments (16). Whatever the biologic significance of the immunoreactive fragments is, there is little doubt that these assay results reflect long-term secretory activity of the parathyroid glands.

In keeping with our preliminary results, approximately two-thirds of subjects with IH have some degree 
TABLE II

Effect of Calcium Infusion on Serum PTH in Four Patients with $I H$ and Hyperparathyroidism

\begin{tabular}{|c|c|c|c|}
\hline \multirow{2}{*}{$\begin{array}{l}\text { Patient } \\
\text { no. }\end{array}$} & \multirow[b]{2}{*}{ Time } & \multicolumn{2}{|c|}{ Serum } \\
\hline & & Total calcium & PTH \\
\hline & & $\mathrm{mg} / 100 \mathrm{ml}$ & $\mu l / m l$ \\
\hline \multirow[t]{2}{*}{80} & Control $^{*}$ & 9.25 & 165 \\
\hline & $2 \mathrm{~h} \ddagger$ & 11.19 & 115 \\
\hline . & $4 \mathrm{~h}$ & 14.08 & 72 \\
\hline \multirow[t]{3}{*}{37} & Control & 9.45 & 255 \\
\hline & $2 \mathrm{~h}$ & 10.99 & 189 \\
\hline & $4 \mathrm{~h}$ & 13.91 & 114 \\
\hline \multirow[t]{3}{*}{93} & Control & 9.96 & 160 \\
\hline & $2 \mathrm{~h}$ & 12.14 & 91 \\
\hline & $4 \mathrm{~h}$ & 14.84 & 56 \\
\hline \multirow[t]{3}{*}{70} & Control & 9.60 & 176 \\
\hline & $2 \mathrm{~h}$ & 50.45 & 117 \\
\hline & $4 \mathrm{~h}$ & 11.50 & 88 \\
\hline
\end{tabular}

* Control samples were drawn immediately before the onset of calcium infusion.

¥ Times refer to hours of intravenous calcium infusion at a rate of $4 \mathrm{mg} / \mathrm{kg}$ per $\mathrm{h}$.

of hyperparathyroidism evidenced by increased serum PTH levels (20). The remaining one-third are normal in this respect. No clear demarcation separates these two types of patients; serum PTH levels are smoothly distributed from normal to high values. Although separation is not complete, serum PTH levels are distinctly higher in subjects with persistent than in those with intermittent hypercalciuria. Patients with persistent hypercalciuria may be more prone to hyperparathyroidism because they have larger average calcium losses and a consequently more profound disruption of calcium homeostasis than patients with intermittent hypercalciuria. It is equally possible that hypercalciuric patients with high and normal PTH levels represent two forms of a heterogeneous disease rather than more or less severe forms of a single illness.

Mechanism of hyperparathyroidism in IH. The pressent data suggest that hyperparathyroidism in IH is secondary to hypercalciuria itself rather than a primary event. Hyperparathyroidism reversed consistently when hypercalciuria was diminished by trichlormethiazide. Lowering of PTH levels by this agent was not due to the induction of hypercalcemia because serum calcium levels failed to rise in nine, and actually fell in two of the 12 subjects. Similarly, trichlormethiazide does not depress $\mathrm{PTH}$ in a nonspecific manner since it did not alter serum PTH levels in the subjects who had normal PTH levels before treatment. Thus, reversal of hyper- parathyroidism by thiazide is best explained as a result of decreased urinary calcium losses, and, as a corollary, hyperparathyroidism in $\mathrm{IH}$ must be due, at least in part, to hypercalciuria.

This conclusion is strongly reinforced by the fact that induction of hypercalciuria in normal subjects by furosemide resulted in hyperparathyroidism equivalent to that observed in patients with the persistent form of IH. Treatment with this drug produced no change in serum total or ionized calcium, serum phosphorus or glomerular filtration rate, so that none of the usual stimuli to PTH secretion were evoked $(19,21,22)$. Since the only dislocation of calcium metabolism this drug produced was hypercalciuria, it seems reasonable
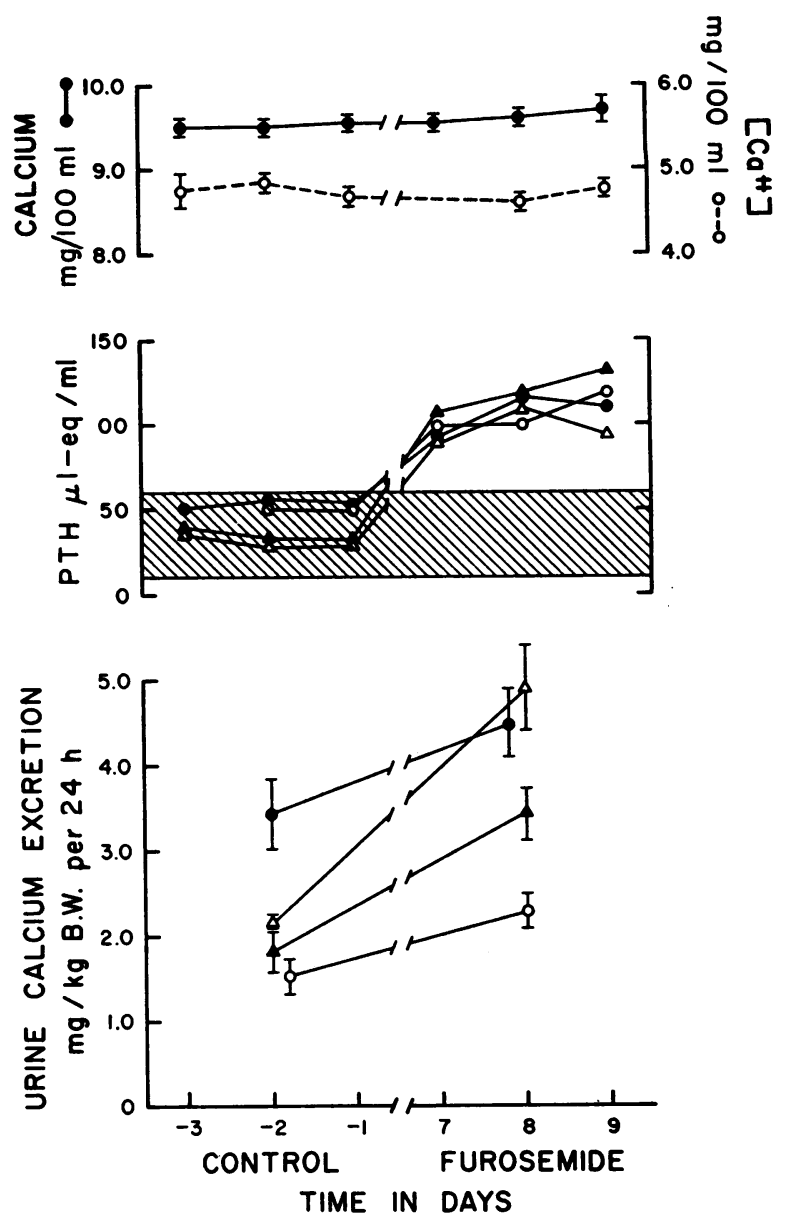

FIGURE 6 Effects of furosemide-induced hypercalciuria upon serum PTH and total and ionized calcium concentrations in normal subjects. Urinary calcium excretion is shown for each subject as the mean $\pm 1 \mathrm{SE}$ for 3 consecutive control days and days 7, 8, and 9 of furosemide administration. Serum PTH values are single determinations for each patient. Serum calcium concentrations are shown as means $\pm 1 \mathrm{SE}$ for all four subjects during control and experimental periods. B. W., body weight. 
to assume that excessive renal calcium loss in some manner provoked hyperparathyroidism. This makes plausible the notion that serum PTH levels are elevated in IH by hypercalciuria itself.

The notion that hyperparathyroidism may be secondary to hypercalciuria is also supported by the fact that PTH levels were lowered appreciably by calcium infusion. Such suppression is characteristic of hyperplasia, the usual anatomical basis for secondary hyperparathyroidism, but not of parathyroid adenomas (14).

Implication for the mechanism of hypercalciuria. Whether or not alimentary hyperabsorption is a mechanism of hypercalciuria in patients who have normal PTH levels cannot be decided on the basis of our current data; however, it is unlikely that $\mathrm{IH}$ results mainly from alimentary hyperabsorption of calcium in those patients who have hyperparathyroidism. Hyperabsorption could lead to normal or suppressed but not high serum PTH levels. In the well-studied example of sarcoidosis, where alimentary hyperabsorption is generally considered to be the major cause of hypercalciuria, serum PTH levels, measured by this immunoassay, were very low (13). The finding of high serum PTH levels in two-thirds of patients with IH may explain why alimentary hyperabsorption of calcium has been found in many patients with this syndrome $(5,7)$. Parathyroid hormone has a weak but distinct action to increase alimentary calcium absorption (23). Possibly the high serum PTH levels in IH increase gastrointestinal calcium absorption. Overall, alimentary hyperabsorption could be the cause of IH in those patients with normal PTH levels, but could not explain the occurrence of $\mathrm{IH}$ with hyperparathyroidism.

The fact that hyperparathyroidism found in IH reverses when hypercalciuria is suppressed with thiazide makes it highly unlikely that a normocalcemic form of primary hyperparathyroidism is the basis of this disorder. In addition, hyperparathyroidism was clearly absent in one-third of patients with IH. Primary hyperparathyroidism, as this disease is usually conceived, is therefore not an attractive mechanism for either form of IH. However, the slightly increased serum calcium in patients with the high $\mathrm{PTH}$ form of $\mathrm{IH}$ indicates that the normal relations between serum calcium and $\mathrm{PTH}$ were disrupted in this subgroup $(21,24)$. This abnormality resembles primary chief cell hyperplasia, but in IH the apparently disturbed failure of feedback control operates at a much lower serum calcium concentration (14). To the extent that this may be named a new form of primary hyperparathyroidism, the issue becomes one of semantics.

The remaining mechanism, a defect of renal tubular calcium reabsorption, provides a unitary explanation of IH, because it could be the basis for hypercalciuria both in patients with elevated and with normal PTH levels.
Primary renal hypercalciuria from furosemide elevated PTH levels in normal people. Patients with $\mathrm{IH}$ and high PTH levels could be analogous to these treated subjects. Normal PTH levels in $\mathrm{IH}$ do not exclude a renal leak. They could reflect smaller average calcium losses, due perhaps to a less severe renal defect. This would explain why PTH levels are generally lower in intermittent than in persistent IH. Alternatively, the high and normal PTH forms of IH may be based upon fundamentally different mechanisms.

\section{ACKNOWLEDGMENTS}

This work was supported in part by Grants AM 08572 and RR 5476, both from the National Institutes of Health, the Noah and Belle Sloan Fund, and the Jules J. Reingold Trust.

\section{REFERENCES}

1. Henneman, P. H., P. H. Benedict, A. P. Forbes, and H. R. Dudley. 1958. Idiopathic hypercalciuria. N. Engl. J. Med. 259: 802 .

2. Hodgkinson, A., and L. N. Pyrah. 1958. The urinary excretion of calcium and inorganic phosphate in 344 patients with calcium stone of renal origin. Br. J. Surg. 46: 10.

3. Blacklock, N. J. 1969. The pattern of urolithiasis in the Royal Navy. In Proceedings of the Renal Stone Research Symposium. A. Hodgkinson and B. E. C. Nordin, editors. J. \& A. Churchill, Ltd., London. 33.

4. Yendt, E. R. 1970. Renal Calculi. Can. Med. Assoc. J. $102: 479$.

5. Liberman, U. A., O. Sperling, A. Atsmon, M. Frank, M. Modan, and A. deVries. 1968. Metabolic and calcium Kinetic studies in idiopathic hypercalciuria. J. Clin. Invest. $47: 2580$.

6. Edwards, N. A., and A. Hodgkinson. 1965. Metabolic studies in patients with idiopathic hypercalciuria. Clin. Sci. 29: 143 .

7. Dent, C. A., and L. Watson. 1965. Metabolic studies in a patient with idiopathic hypercalciuria. $B r . M e d . J .2$ : 449.

8. Wills, M. R., C. Y. Pak, W. G. Hammond, and F. C. Bartter. 1969. Normocalcemic primary hyperparathyroidism. Am. J. Med. $47: 384$.

9. Nichols, G. Jr., and B. Flanagan. 1967. Normocalcemic hyperparathyroidism. Trans. Assoc. Am. Physicians (Phila.). 80: 314.

10. Kleeman, C. R., O. Better, S. G. Massry, and M. H. Maxwell. 1967. Divalent ion metabolism and osteodystrophy in chronic renal failure. Yale J. Biol. Med. 40: 1 .

11. Finn, W. F., G. J. Cerilli, and T. F. Ferris. 1970. Transplantation of a kidney from a patient with idiopathic hypercalciuria. N. Engl. J. Med. 283: 1450.

12. Reiss, E., and J. M. Canterbury. 1968. A radioimmunoassay for parathyroid hormone in man. Proc. Soc. Exp. Biol. Med. 128: 501.

13. Cushard, W. G., Jr., A. B. Simon, J. M. Canterbury, and E. Reiss. 1972. Parathyroid function in sarcoidosis. N. Engl. J. Med. 286: 395.

14. Reiss, E., and J. M. Canterbury. 1971. Genesis of hyperparathyroidism. Am. J. Med. 50: 679. 
15. Habener, J. F., D. Powell, T. M. Murray, G. P. Mayer, and J. T. Potts, Jr. 1971. Parathyroid hormone: secretion and metabolism in vivo. Proc. Natl. Acad. Sci. U.S. A. $68: 2986$.

16. Canterbury, J. M., and E. Reiss. 1972. Multiple immunoreactive molecular forms of parathyroid hormone in human serum. Proc. Soc. Exp. Biol. Med. 140: 1393.

17. Forscher, B. K., and C. D. Arnaud, editors. 1971. F. Raymond Keating, Jr., Memorial Symposium-Hyperparathyroidism, 1970. Am. J. Med. 50: 557.

18. Segre, G. V., J. F. Habener, D. Powell, H. Keutmann, G. Tregear, and J. T. Potts, Jr. 1972. Development and application of sequence specific radioimmunoassays (RIAs) for parathyroid hormone (PTH) in man. Clin. Res. 20: 440. (Abstr.)

19. Reiss, E., J. M. Canterbury, M. A. Bercovitz, and E. L. Kaplan. 1960. The role of phosphate in the secretion of parathyroid hormone in man. J. Clin. Invest. 49: 2146.
20. Coe, F. L., J. Canterbury, and E. Reiss. 1971. Hyperparathyroidism in idiopathic hypercalciuria: primary or secondary? Trans. Assoc. Am. Physicians (Phila.). 84: 152.

21. Sherwood, L. M., G. P. Mayer, C. F. Ramberg, Jr., D. S. Kronfield, G. D. Aurbach, and J T. Potts, Jr. 1968. Regulation of parathyroid hormone secretion: proportional control by calcium, lack of effect of phosphate. Endocrinology. 83: 1043.

22. Reiss, E., J. M. Canterbury, and A. Kanter. 1969. Circulating parathyroid hormone concentration in chronic renal insufficiency. Arch. Intern. Med. 124: 417.

23. Rasmussen, H. 1968. The parathyroids. In Textbook of Endocrinology. R. H. Williams, editor. W. B. Saunders Company, Philadelphia. 886.

24. Arnaud, C. D., H. S. Tsao, and T. Littledike. 1971. Radioimmunoassay of human parathyroid hormone in serum. J. Clin. Invest. 50: 21. 